Int. J. Electrochem. Sci., 12 (2017) $9588-9600$

\title{
Simple Fabrication of Nickel Sulfide Nanostructured Electrode Using Alternate Dip-Coating Method and Its Supercapacitive Properties
}

\author{
Jinhyeon Kang, Ilhwan Ryu, Geunpyo Choe, Green Kim, Sanggyu Yim* \\ Department of Chemistry, Kookmin University, Seoul 136-702, South Korea \\ "E-mail: sgyim@kookmin.ac.kr
}

doi: $10.20964 / 2017.10 .27$

Received: 21 June 2017 / Accepted: 4 August 2017 / Published: 12 September 2017

\begin{abstract}
In order to make best use of the superior electrochemical properties of nickel sulfide (NiS) as an electrode material for supercapacitors, increase in surface area through electrode nanostructuring is one of the major issues. However, currently used NiS nanostructuring methods, such as hydrothermal and solvothermal techniques, require high-temperature, long and complicated nano-processes, and hence are not suitable for practical use. In this work, we developed a new, simple method for fabricating porous, nanostructured $\mathrm{NiS}$ electrodes by dipping a titanium oxide $\left(\mathrm{TiO}_{2}\right)$ nanoparticle-deposited substrate in nickel acetate and sodium sulfide solutions, alternately, at room temperature. One cycle of this alternate dip-coating process takes only $6 \mathrm{~min}$ and the amount of deposited NiS can be easily controlled by the number of deposition cycles. Maximum specific capacitance $\left(C_{\mathrm{sp}}\right)$ of $1044 \mathrm{~F} / \mathrm{g}$, comparable to the values of previously reported NiS nanostructure electrodes, was obtained. The voltammetric response retention at high scan rates was also improved by the nanostructuring, exhibiting a value 1.5 times larger than that of the planar film electrode.
\end{abstract}

Keywords: supercapacitor, nickel sulfide, nanostructured electrode, alternate dip-coating.

\section{$\underline{\text { FULL TEXT }}$}

(C) 2017 The Authors. Published by ESG (www.electrochemsci.org). This article is an open access article distributed under the terms and conditions of the Creative Commons Attribution license (http://creativecommons.org/licenses/by/4.0/). 